\title{
Spirometric data and penetration of particles to the alveoli
}

\author{
M SVARTENGREN, E HASSLER, K PHILIPSON, AND P CAMNER
}

From the Department of Environmental Hygiene, Karolinska Institute, and Section of Inhalation Toxicology, Department of Toxicology, National Institute of Environmental Medicine, S-104 01 Stockholm, Sweden

ABSTRACT The percentage retention at 24 hours of $4 \mu \mathrm{m}$ Teflon particles, aerodynamic diameter about $6 \mu \mathrm{m}$, was studied in 29 healthy male volunteers. The particles were inhaled at $0.51 / \mathrm{s}$ with

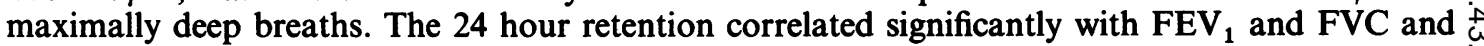
persisted when the subjects were divided into different categories according to profession and $\dot{\omega}$ smoking habits. The results suggest that for exposure to metal particles at a size where impaction $\vec{\infty}$ is an important deposition mechanism-that is, particles larger than a few microns-workers with large $\mathrm{FEV}_{1}$ values may run a greater risk of receiving systemic toxic effects than those with small $\mathrm{FEV}_{1}$ values.

The elimination of intact particles that have settled in the alveolar part of the lung is extremely slow, the most of such particles being removed with a half time in the order of magnitude of one to several years. ${ }^{1-3}$ The particles are cleared not only by the removal of whole particles but also by dissolution. Dissolution is also an important elimination mechanism for metal particles usually considered insoluble. ${ }^{4-8}$ For many aerosols of metal particles the fraction deposited in the alveolar part of the lung will enter the bloodstream and may cause systemic toxic effects. For example, less soluble lead particles have been shown to enter the bloodstream rather quickly. ${ }^{9}$ Particles deposited on the tracheobronchial tree are transported by the mucociliary escalator or coughing to the larynx where they are swallowed. As most metals are absorbed into the bloodstream from the gastrointestinal tract to a small degree, less soluble metal particles that are deposited in the tracheobronchial tract will not cause systemic toxic effects.

In an earlier study we found that the $\mathbf{2 4}$ hour lung retention of inhaled $4 \mu \mathrm{m}$ (aerodynamic diameter $6 \mu \mathrm{m})$ Teflon particles varied considerably within a group of 10 healthy men, but that the variation of the 24 hour retention was small for each individual. ${ }^{10}$ The aim of the present study was to investigate whether there is a correlation between the retention of these Teflon particles after 24 hours and lung function tests such as forced expiratory volume in one second $\left(\mathrm{FEV}_{1}\right)$ and forced vital capacity (FVC).

Accepted 27 September 1985

\section{Subjects and methods}

Of the 29 healthy men studied, 11 were students and people working at the university and are referred to as "students." Alveolar retention data on 10 of the 11 ำ students have been published previously. ${ }^{10}$ Since duplicate measurements were performed in those $10 \%$ men, mean values of the two measurements were used. The other 18 men were workers from a battery fac- $\overrightarrow{\overrightarrow{0}}$ tory. Table 1 shows age, smoking habits, and spi- 3 rometric data. Owing to the small number of subjects, two ex-smokers who had stopped smoking two and 22 . years before the investigation were included in the ${ }_{\bar{\Phi}}$ non-smoking group. This is justified by the fact that 3 trachobronchial clearance improves for former smokers three months after they stop smoking and. clearance becomes similar to that of non-smokers. ${ }^{12} \odot$ Of the 10 smokers, two were pipesmokers, one a combined pipe and cigarette smoker, and seven음 cigarette smokers. Tobacco consumption expressed as $\supset$ cigarettes a day was: one smoker (3 cigarettes), two으․ smokers (15) and seven smokers (20).

The Teflon particles were produced and labelled . with ${ }^{111}$ In (half life 2.83 days) by a spinning disc $N$ technique. ${ }^{1314}$ The students inhaled $4 \cdot 2 \pm 0.7$ and $4 \cdot 3$ N $\pm 0.8 \mu \mathrm{m}$ (mean \pm SD) Teflon particles and the workers $3.9 \pm 0.4 \mu \mathrm{m}$ particles. For details of the exposure technique see Camner and Philipson. ${ }^{10}$ The subjects inhaled the test particles with 10-20 max-? imally deep inhalations. The flow rate was registered 0 on a recorder and by looking at the recorder, the subjects could inhale with a constant flow at about $\stackrel{\oplus}{\circ}$ 
Table 1 Personal and spirometric data.

\begin{tabular}{|c|c|c|c|c|c|c|}
\hline & \multicolumn{2}{|c|}{ Students } & \multicolumn{4}{|c|}{ Workers } \\
\hline & \multicolumn{2}{|c|}{ Non-smokers $(n=11)$} & \multicolumn{2}{|c|}{ Non-smokers $(n=8)$} & \multicolumn{2}{|c|}{ Smokers $(n=10)$} \\
\hline & Mean & $(S D)$ & Mean & $(S D)$ & Mean & $(S D)$ \\
\hline $\begin{array}{l}\text { Age (years) } \\
\text { Weight (kg) } \\
\text { Height (cm) } \\
\text { FEV } 1 \text { (l) } \\
\left.\text { FEV } 1 \text { (\% of predicted }{ }^{*}\right) \\
\text { FVC }(1) \\
\text { FVC (\% of predicted*) }\end{array}$ & $\begin{array}{c}26 \\
76 \\
181 \\
5 \cdot 0 \\
103 \\
6 \cdot 0 \\
102\end{array}$ & $\begin{array}{l}(7) \\
(6) \\
(5 \cdot 6) \\
(0 \cdot 65) \\
(9 \cdot 8) \\
(0 \cdot 75) \\
(10 \cdot 0)\end{array}$ & $\begin{array}{c}47 \\
82 \\
172 \\
4 \cdot 1 \\
111 \\
5 \cdot 1 \\
104\end{array}$ & $\begin{array}{l}(11) \\
(11) \\
(6 \cdot 9) \\
(0 \cdot 86) \\
(16 \cdot 7) \\
(1 \cdot 13) \\
(17 \cdot 7)\end{array}$ & $\begin{array}{c}46 \\
75 \\
176 \\
4 \cdot 2 \\
108 \\
5 \cdot 5 \\
107\end{array}$ & $\begin{array}{l}(11) \\
(10) \\
(7 \cdot 1) \\
(0 \cdot 93) \\
(13 \cdot 3) \\
(0 \cdot 81) \\
(9 \cdot 1)\end{array}$ \\
\hline
\end{tabular}

*According to the formula of Berglund et al. ${ }^{11}$

$0.51 / \mathrm{s}$, as trained before exposure. Immediately after inhalation of the test aerosol and after 24 hours (24-26 hours) after the inhalation the radioactivity in the lungs was measured with a profile scanner with two $3 \times 2$ inches $\mathrm{NaI}$ crystals fitted with collimators. ${ }^{1314}$

FEV $_{1}$ and FVC were measured on the same day as the inhalation of the test particles with a Vitalograph spirometer with the subject in a standing position.

\section{Results}

In the figure the $\mathrm{FEV}_{1}$ values are plotted against the percentage retention at 24 hours for the students, non-
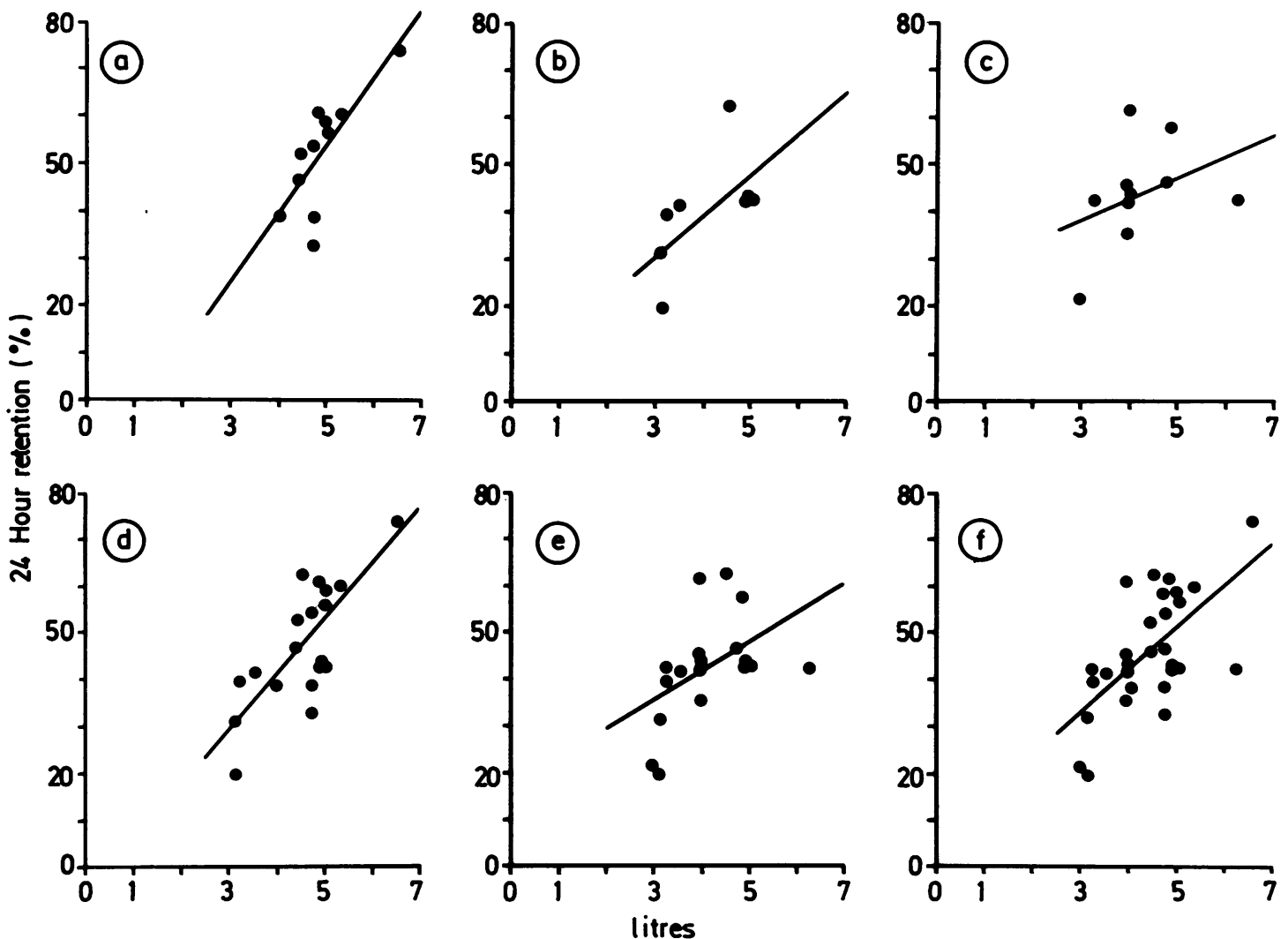

Correlation between 24 hour lung retention of ${ }^{111}$ In labelled $4 \mu \mathrm{m}$ Teflon particles in percentage of first observed value and FEV $V_{1}$ ( $(a)=$ Non-smoking "students," $(b)=$ non-smoking workers, $(c)=$ smoking workers, $(d)=(a)+(b)$, $(e)=(b)+(c)$, and $(f)=(a)+(b)+(c)$. 
Table 2 Correlations between spirometric values (FEV and FVC) and percentage particle retention at 24 hours.

\begin{tabular}{|c|c|c|c|c|c|c|c|}
\hline & & \multirow{2}{*}{$\begin{array}{l}\text { "Students" (a) } \\
(n=11)\end{array}$} & \multicolumn{2}{|l|}{ Workers } & \multirow{2}{*}{$\begin{array}{l}\text { all non-smokers } \\
(a+b) \\
(n=19)\end{array}$} & \multirow{2}{*}{$\begin{array}{l}\text { all workers } \\
(b+c) \\
(n=18)\end{array}$} & \multirow{2}{*}{$\begin{array}{l}\text { all subjecti } \\
(a+b \text { t } \\
\left(n=29 \frac{5}{C}\right.\end{array}$} \\
\hline & & & $\begin{array}{l}\text { Non-smokers (b) } \\
(n=8)\end{array}$ & $\begin{array}{l}\text { Smokers }(c) \\
(n=10)\end{array}$ & & & \\
\hline \multirow[t]{2}{*}{$\begin{array}{l}\mathrm{FEV}_{1}(1) \text {-retention at } \\
24 \mathrm{hrs}(\%)\end{array}$} & $\begin{array}{l}\text { Coefficient of correlation } \\
\text { (r) }\end{array}$ & $\begin{array}{l}0 \cdot 76 \\
14 \cdot 1\end{array}$ & $\begin{array}{l}0 \cdot 61 \\
8 \cdot 6\end{array}$ & $\begin{array}{l}0 \cdot 38 \\
4 \cdot 5\end{array}$ & $\begin{array}{l}0 \cdot 75 \\
11 \cdot 7\end{array}$ & $\begin{array}{l}0 \cdot 48 \\
6 \cdot 3\end{array}$ & $\begin{array}{l}0.64 \\
9 \cdot 0\end{array}$ \\
\hline & $\begin{array}{l}\text { p value, aiverge } \\
\text { from zero } \\
1 \% \text { coincidence interval }\end{array}$ & $\begin{array}{l}\mathrm{p}<0.01 \\
(0.89-27 \cdot 3)\end{array}$ & $0.1<p<0.2$ & $0.2<p<0.4$ & $\begin{array}{l}p<0.001 \\
(4.46-18.94)\end{array}$ & $\underline{p}<0.05$ & $\begin{array}{l}\mathrm{p}<0.009) \\
(3.18-14.7\end{array}$ \\
\hline \multirow[t]{2}{*}{$\begin{array}{l}\text { FVC (1)-retention at } \\
24 \mathrm{hrs}(\%)\end{array}$} & $\begin{array}{l}\text { Coefficient of correlation } \\
\text { (r) } \\
\text { Slope, \%/l } \\
\text { p Value, diverge }\end{array}$ & $\begin{array}{l}0.49 \\
7.8\end{array}$ & $\begin{array}{l}0 \cdot 60 \\
6 \cdot 4\end{array}$ & $\begin{array}{l}0.42 \\
5.7\end{array}$ & $\begin{array}{l}0 \cdot 62 \\
8 \cdot 2\end{array}$ & $\begin{array}{l}0.52 \\
6 \cdot 2\end{array}$ & $\begin{array}{l}0 \cdot 57 \\
7 \cdot 6\end{array}$ \\
\hline & $\begin{array}{l}\text { from zero } \\
1 \% \text { coincidence interval }\end{array}$ & $\underline{0.1}<\mathrm{p}<0.2$ & $0.1<p<0.2$ & $\underline{0.2}<p<0.4$ & $\begin{array}{l}p<0.01 \\
(0.95-15.37)\end{array}$ & $\underline{p}<0.05$ & $\begin{array}{l}p<0.006 \\
(1.80-13 . \pm 19\end{array}$ \\
\hline
\end{tabular}

smoking workers, smoking workers, all non-smokers, all workers, and all subjects. The correlation coefficients, slopes, and $p$ values for the various groups shown in the figure and corresponding data on the correlation between FVC and the percentage particle retention at 24 hours are shown in table 2. Both $\mathrm{FEV}_{1}$ and FVC correlate significantly with the 24 hour retention for all non-smokers, all smokers, and all subjects $(\mathrm{p}<0.05)$. For the students there is also a significant correlation between $\mathrm{FEV}_{1}$ and the 24 hour retention. There is an overall tendency for a better correlation between $\mathrm{FEV}_{1}$ and retention than between FVC and retention.

\section{Discussion}

Particles deposited in the tracheobronchial tract in some animal experiments have been retained for more than 24 hours. For rabbits, $71 \%$ of intratracheally administered Teflon particles deposited at the first bifurcation cleared with a mean half time of $39 \cdot 0$ hours. ${ }^{15}$ Using the same inhalation exposure technique as in the present study, however, Camner and Philipson found a similar retention after one and three days, ${ }^{10}$ suggesting that there could have been no large fractions which cleared with a half time of about 40 hours. The 24 hour retention represents particles that are cleared slowly from the lung, probably those deposited in the alveolar or non-ciliated part of the lung - the respiratory bronchioli, alveolar ducts, and alveoli.

With the rather large particles inhaled with maximum deep inhalation at $0.51 / \mathrm{sec}$, almost all the particles which reached the non-ciliated part of the lung should have been deposited. ${ }^{16}$ As the dead space volume is small compared with the inhaled volume (about $5 \%$ when 31 is inhaled), the percentage 24 hour retention should be almost independent of the inhaled volume. Assuming a pause of $2 \mathrm{~s}$ after the inhalation of $4 \mu \mathrm{m}$ Teflon particles at $0.51 / \mathrm{s}$ the percentage of particles deposited in the alveoli is calculated to differ by only $1 \%$ between an inhaled volume of 31 and one of 61 , using the lung model and equations of the Task Group on Lung Dynamics. ${ }^{16}$ Thus differences in inhaled volume have probably not affected the 24 hour retention values in our study to any great degree.

The correlation between the spirometric values and 24 hour retention was studied in a heterogenous group of healthy male volunteers. When the subjects were divided into groups by profession and smoking habits, all showed similar trends. The smokers had the lowest correlation between the spirometric values and retention. In this group a lower correlation is expected since long term smoking can impair mucociliary transport ${ }^{1718}$ and this 24 hour retention might include particles in the tracheobronchial tract. Mucociliary clearance has been found to decrease with age. ${ }^{1920}$ The students in our study were younger than the smoking and non-smoking workers. Nevertheless, there was a similar correlation between FEV or FVC and the $\mathbf{2 4}$ hour retention in all three groups. Furthermore, the retention at FEV 1 values of 41 (estimated from the regression lines) were $39 \%, 40 \%$, and $43 \%$ in the students, non-smoking workers, and smoking workers respectively. Thus it is not probable that age differences have affected our results to any substantial degree.

For the relatively large test particles (ca $6 \mu \mathrm{m}$ aerodynamic diameter) inhaled at $0.51 / \mathrm{s}$, impaction is an important mechanism for the deposition in the tracheobronchial tract. ${ }^{16}$ This implies that subjects with larger bronchial diameters will have a larger fraction deposited in the alveolar part of the lung because the air velocity in the bronchi decreases with increasing diameter. As FVC and especially FEV $_{1}$ correlate positively with the dimension of the bronchi, the positive correlation between FEV 1 or FVC and retention is not unreasonable. In patients with airways obstruc- 
tion (and reduced $\mathrm{FEV}_{1}$ ) $5 \mu \mathrm{m}$ polystyrene particles and $3 \mu \mathrm{m}$ (aerodynamic diameter) albumin particles penetrate the tracheobronchial tract to a lesser degree than in healthy subjects. ${ }^{21-25}$ Garrard et al studied aerosol deposition in 13 healthy non-smoking subjects using $8.1 \mu \mathrm{m}$ aerodynamic diameter $\mathrm{Fe}_{2} \mathrm{O}_{3}$ particles labelled with ${ }^{99 \mathrm{~m}} \mathrm{Tc}^{26} \mathrm{FEV} \%$ correlated with the 24 hour retention $(r=0.45)$ but $F V_{1}$ did not $(r=0.21)$. The lack of significant correlation between $\mathrm{FEV}_{1}$ and the 24 hour retention might be explained by the small 24 hour retention, $12.8 \pm 8.6 \%$ (mean $\pm S D$ ) in their study.

In this study and in the study by Camner and Philipson, ${ }^{10}$ using the same particles and inhalation pattern, the 24 hour retention varied largely among subjects. As the retention values were reproducible, ${ }^{10}$ the differences must be due to individual factors. In real life the amount of particulate material deposited in the alveolar part of the lung depends inter alia on the amount of air inhaled, on the particulate concentration in the air, on whether mouth or nose breathing is used, and on the fraction of particles deposited in the whole lung. Nevertheless, the large differences in the percentage 24 hour retention suggest that under similar conditions, subjects with high retention values will also have a larger amount of deposited particles in the alveoli than subjects with low retention values. This is true when inhaled aerosols consist of relatively large particles, greater than about $2 \mu \mathrm{m}$. Impaction is an important mechanism for deposition in the tracheobronchial tract for such particles. ${ }^{16}$ In our study artificial conditions were used but in working situations, where tidal volumes are large compared with the dead space, the 24 hour retention will probably not differ much from that in our experiment.

The high correlation between the $\mathrm{FEV}_{1}$ values and the 24 hour percentage retention suggests that workers with large $\mathrm{FEV}_{1}$ may be at higher risk of systemic toxic effects from metal particles than their colleagues with lower $\mathrm{FEV}_{1}$. In epidemiological studies it would be of value if groups with various degrees of exposure had similar FEV $_{1}$ values.

We are grateful for skilled technical help from Ms Karin Widtskiöld-Olsson. This study was supported by a grant from the Swedish Work Environment Foundation.

\section{References}

${ }^{1}$ Bohning DE, Atkins HL, Cohn SH. Long-term particle clearance in man: normal and impaired. Ann Occup Hyg 1982;26:259-71.

${ }^{2}$ Bailey MR, Fry FA, James AC. The long-term clearance kinetics of insoluble particles from the human lung. Ann Occup Hyg 1982;26:273-90.
${ }^{3}$ Philipson K, Falk R, Camner P. Long-term lung clearance in humans studied with Teflon particles labelled with ${ }^{51} \mathrm{Cr}$. Exp Lung Res 1985;9:31-42.

${ }^{4}$ Morrow PE, Gibb FR, Johnson L. Clearance of insoluble dust from the lower respiratory tract. Health Phys 1964;10:543-55.

${ }^{5}$ Morrow PE, Gibb FR, Gazioglu KM. A study of particulate clearance from the human lungs. Am Rev Respir Dis 1967;96:1209-21.

${ }^{6}$ Mercer TT. On the role of particle size in the dissolution of lung burdens. Health Phys 1967;13:1211-21.

${ }^{7}$ Moss OR, Kanapilly GM. Dissolution of inhaled aerosols. In: Willeke K, ed. Generation of aerosols and facilities for exposure experiments. Ann Arbor: Science Publishes Inc, 1980:105-24.

${ }^{8}$ Lundborg M, Lind B, Camner P. Ability of rabbit alveolar macrophages to dissolve metals. Exp Lung Res 1984;7:11-22.

${ }^{9}$ Chamberlain AC, Heard MJ, Little D, Newton AC, Wiffen RD. Investigations into lead from motor vehicles. Harwell: AERE, 1978.

${ }^{10}$ Camner P, Philipson K. Human alveolar deposition of $4 \mu \mathrm{m}$ Teflon particles. Arch Environ Health 1978;33:181-5.

${ }^{11}$ Berglund E, Birath G, Bjure J, et al. Spirometric studies in normal subjects. Acta Med Scand 1963;173:185-205.

${ }^{12}$ Camner P, Philipson K, Arvidsson T. Withdrawal of cigarette smoking. A study on tracheobronchial clearance. Arch Environ Health 1973;26:90-2.

${ }^{13}$ Camner P. The production and use of test aerosols for studies of human tracheobronchial clearance. Environmental Physiology 1971;1:137-54.

${ }^{14}$ Philipson K. Monodisperse labelled aerosols for studies of lung clearance. In: Abstracts of Uppsala. Dissertations from the Faculty of Science 433. Uppsala: Almqvist \& Wiksell, 1977.

${ }^{15}$ Svartengren M, Widtskiöld-Olsson K, Philipson K, Camner P. Retention of particles on the first bifurcation and trachea of rabbits. Clin Respir Physiol 1981;17:87-91.

${ }^{16}$ Task Group on Lung Dynamics. Deposition and retention models for internal dosimetry of the human respiratory tract. Health Phys 1966;12:173-207.

${ }^{17}$ Lourenco RV, Klimek MF, Borowski CJ. Deposition and clearance of $2 \mu$ particles in the tracheobronchial tree of normal subjects-smokers and nonsmokers. J Clin Invest 1971;50: 1411-9.

${ }^{18}$ Camner P, Philipson K. Tracheobronchial clearance in smokingdiscordant twins. Arch Environ Health 1972;25:60-3.

${ }^{19}$ Goodman RM, Yergin BM, Landa JF, Golinvaux MH, Sackner MA. Relationship of smoking history and pulmonary function tests to tracheal mucus velocity in nonsmokers, young smokers, exsmokers and patients with chronic bronchitis. Am Rev Respir Dis 1978;117:205-14.

${ }^{20}$ Puchelle E, Zahn JM, Bertrand A. Influence of age on bronchial mucociliary transport. Scand J Respir Dis 1979;60:307-13.

${ }^{21}$ Pavia D, Thomson M, Shannon HS. Aerosol inhalation and depth of deposition in the human lung. Arch Environ Health 1977;32:131-7.

${ }^{22}$ Pavia D, Thomson ML, Clarke SW, Shannon HS. Effect of lung function and mode of inhalation on penetration of aerosol into the human lung. Thorax 1977;32:194-7.

${ }^{23}$ Agnew JE, Pavia D, Clarke SW. Airways penetration of inhaled radioaerosol: an index to small airways function? Eur J Respir Dis 1981;62:239-55.

${ }^{24}$ Dolovich MB, Sanchis J, Rossman C, Newhouse MT. Aerosol penetrance: a sensitive index of peripheral airways obstruction. J Appl Physiol 1976;40:468-71.

${ }^{25}$ Lippman M, Albert RE, Peterson HT. The regional deposition of inhaled aerosols in man. In: Walton WH, ed. Inhaled particles III. Old Woking: Unwin Brothers, 1971:105-22.

${ }^{26}$ Garrard CS, Gerrity TR, Schreiner JF, Yeates DB. Analysis of aerosol deposition in the healthy human lung. Arch Environ Health 1981;36:180-93. 